\title{
In-Hospital Hip Fractures in Canada: Using Information to Improve Patient Safety
}

\section{Introduction}

Few people anticipate breaking their hip after being admitted to hospital, yet new data demonstrate the magnitude of this problem in Canadian hospitals. Most hip fractures occur in the community, but nearly one in 1,000 seniors admitted to hospital fracture a hip during their stay. Not surprisingly, patient falls or injuries were the second-most-common patient safety concern identified by Canadian healthcare organizations in a 2002 survey (Baker and Norton 2002).

The rate of in-hospital falls for seniors is one of a series of patient safety indicators at the regional, provincial/territorial and national levels, recently developed at the Canadian Institute for Health Information ( $\mathrm{CIHI}$ ). Originally adapted from indicators developed by the U.S. Agency for Health Research and Quality (ARHQ), the CIHI in-hospital hip fracture indicator was tailored for use with Canadian data and in our healthcare system.

\section{Methods and Data Sources}

Data for the analysis were obtained from CIHI's Discharge Abstract Database (DAD) for fiscal years 2000-2002 (April 1, 2000 - March 31, 2003) for inpatient medical and surgical cases aged 65 years and older. ${ }^{1}$

In order to enhance the comparability of these rates and reduce variation due to patient mix, a risk-adjustment model that included factors known to affect the likelihood of hip fracture in hospital was developed. These factors included type of inpatient care (medical vs. surgical), age, sex and several co-morbid conditions. ${ }^{2}$ Patients from Québec and Manitoba were excluded in this analysis due to differences in the way data are collected.

\section{Results}

Overall, one in 1,124 patients 65 years of age or older suffered a hip fracture after admission to hospital ( 0.9 per 1,000 population). This makes hip fractures more common than having a foreign object, such as a sponge or an instrument, left in after a procedure, but less common than hospital-acquired infections and serious tears during childbirth ( $\mathrm{CIHI} 2004)$.

Even after adjusting for age, sex and co-morbidities, provincial and regional rates varied substantially across the country. Provincial rates ranged from 0.8 to 1.3 in-hospital hip

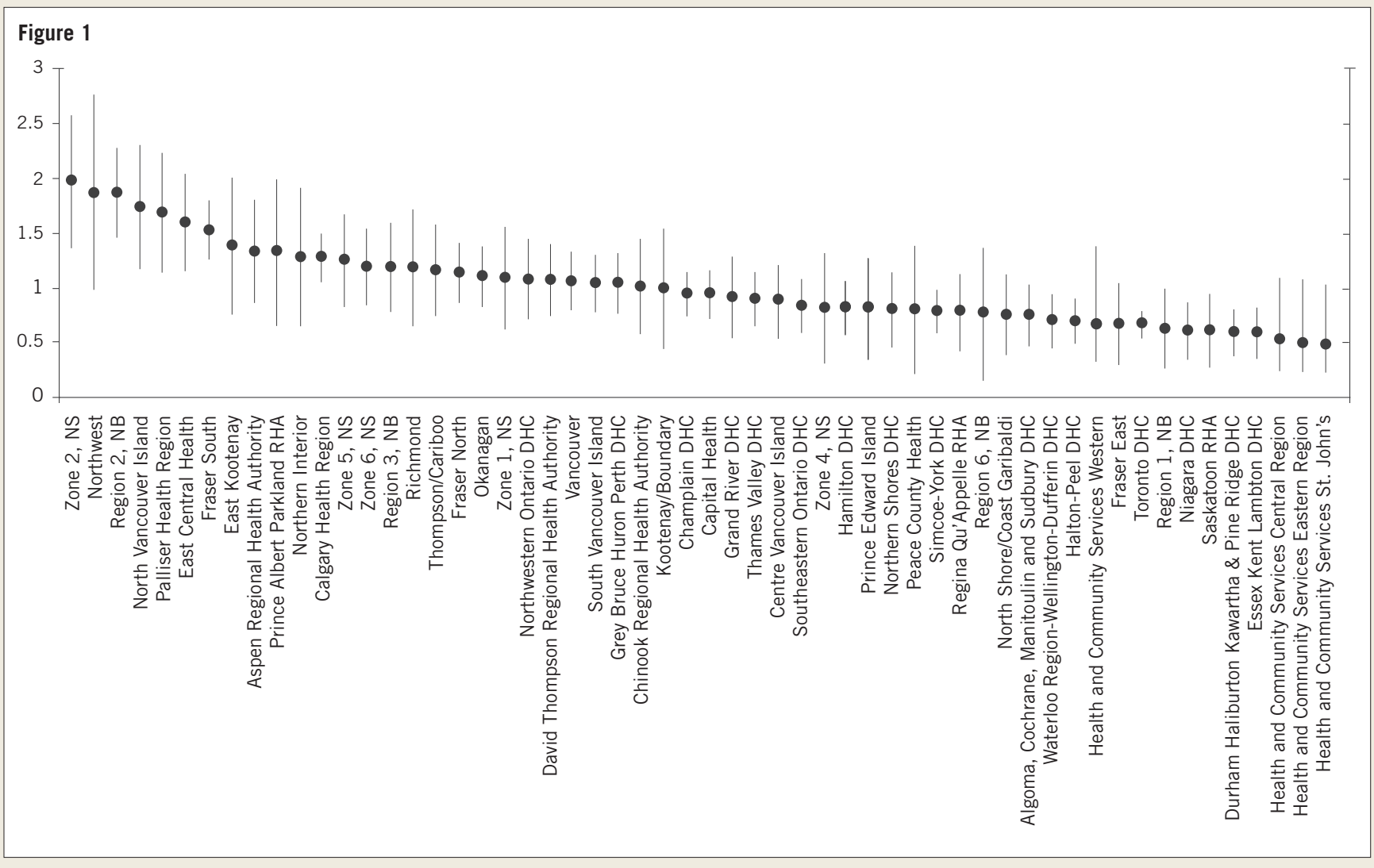

1. Complete technical notes, including a full list of diagnostic codes used, are available at http://secure.cihi.ca/indicators/en/2004_tech_ hip_e.shtml.

2. Co-morbid conditions used in the risk adjustment include cancer, seizure, syncope, stroke, coma, cardiac arrest, anoxic brain injury, poisoning, delirium, other psychosis, trauma and musculoskeletal/connective tissue disorder. 
fractures per 1,000 cases. Not surprisingly, much larger variations were observed at the regional level, where fourfold differences emerged. Rates for regions with populations of more than 75,000 individuals are shown in Figure 1. The rates shown by the dot are estimated to be accurate to within the range shown by the bar, 19 times out of 20 .

In all age groups, females were more prone to breaking a hip in hospital than males. The incidence of in-hospital hip fracture also increased with age, as did the differences between male and female rates (Table 1 ). In the oldest age group, those 90 and older, the risk of in-hospital hip fracture for females (2.4 per 1,000 admissions) was considerably higher than for males (1.4).

Knowing more about who is most at risk can be informative for the development of risk management and injury reduction.

\begin{tabular}{|llcc|}
\hline \multicolumn{3}{|l|}{ Table 1: In-hospital hip fractures by age group and gender } \\
\hline Age Group & Gender & $\begin{array}{c}\text { In-hospital } \\
\text { Fractures }\end{array}$ & Rate* \\
& & 69 & 0.3 \\
65-69 & Male & 82 & 0.5 \\
& Female & 125 & 0.5 \\
$70-74$ & Male & 123 & 0.6 \\
& Female & 138 & 0.6 \\
$75-79$ & Male & 261 & 1.0 \\
& Female & 167 & 0.9 \\
80-84 & Male & 301 & 1.4 \\
& Female & 118 & 1.2 \\
85-89 & Male & 277 & 1.8 \\
& Female & 58 & 1.4 \\
90+ & Male & 207 & 2.4 \\
& Female & 1926 & 0.9 \\
Total & & & \\
${ }^{*}$ Crude rate/1,000 & & & \\
\hline
\end{tabular}

Further analysis was able to shed some light on which types of patients are more likely to suffer an in-hospital hip fracture. Surgical patients, for example, were almost seven times more likely to break a hip in hospital than medical patients. Other high-risk groups include older patients ( 85 years and over), and patients with musculoskeletal or connective tissue disorders, stroke or other co-morbid conditions.

\section{What Does This Indicator Tell Us?}

Patient safety indicators can play an instrumental role in understanding, managing and ultimately reducing adverse events in Canadian hospitals. These data show the extent of this particular patient safety concern - between April 2000 and March 2003, nearly 2000 individuals suffered a broken hip that occurred after admission to an acute care hospital not including patients from Manitoba or Quebec.

For the first time, these indicator data allow health regions and provinces to compare their in-hospital hip fracture rates with other jurisdictions in Canada. The rates for individual hospital sites can be calculated to identify intraregional variations and trends over time, as well as to stimulate the identifi- cation of opportunities to improve patient safety. This indicator can also help assess the burden of in-hospital hip fractures overall, and the extent of variations across Canada.

By itself, an indicator cannot explain these variations. It can, however, serve as a valuable alert, prompting regions with higher rates to launch a more detailed investigation of incident reports or patient charts, consider the risk adjustment, review medication use or examine staffing issues or physical infrastructure, for example.

Understanding who is most at risk - the oldest old, women and surgical patients, for example - is an important consideration when making efforts to reduce in-hospital hip fractures. A variety of factors that could not be captured in this analysis, such as gait and balance disturbances, use of tranquillizers and evidence of previous stroke may also increase the likelihood of in-hospital falls leading to hip fractures (Vassallo and Sharma 2002; Salgado et. al 2004). At the same time, many things within the control of the facility have also been shown to reduce falls and fractures, such as changes in clinical assessments, modifying the physical environment (providing adequate lighting and eliminating spills, for example), using other tools to minimize injury (such as protective equipment including hip protectors or ways to identify high-
Region-specific rates for this indicator as well as their associated confidence intervals can be found in Health Indicators 2004 (PDF), or the Health Indicators E-Publication. Both are available at www.cihi.ca risk patients) and patient and staff education (AHRQ 2003). Experts suggest that fall-prevention strategies in healthcare facilities require a multifaceted approach, which has been shown to be effective in reducing the incidence of in-hospital falls (Robbins et al. 1989).

The in-hospital hip fracture rate can be used to identify opportunities for improving patient safety. If substantial efforts are made to ensure improvements in this area, this indicator may also prove to be an effective tool for demonstrating future reductions in in-hospital hip fractures and improvements in patient safety.

\section{About the Authors \\ Indra Pulcins, $\mathrm{PhD}$, is Manager of Health Indicators at the Canadian Institute for Health Information $\mathrm{CIHI}$.}

Eugene Wen, DrPH, is a Senior Consultant for Health Indicators at the Canadian Institute for Health Information $\mathrm{CIHI}$.

\section{References}

Agency for Healthcare Research and Quality. 2001. "Making Health Care Safer. A Critical Analysis of Patient Safety Practices Evidence Report/Technology Assessment, No. 43. AHRQ Publication 01-E058. Rockville, MD: Agency for Healthcare Research and Quality. 
Agency for Healthcare Research and Quality. 2003. AHRQ Quality Indicators - Guide to Patient Safety Indicators. AHRQ Publication 03R203. Rockville, MD: Agency for Healthcare Research and Quality.

Baker, G.R. and P. Norton. 2002. "Patient Safety and Healthcare Error in the Canadian Healthcare System: A Systematic Review and Analysis of Leading Practices in Canada with Reference to Key Initiatives Elsewhere." A Report to Health Canada. Ottawa: Health Canada. <http://www.hc-sc.gc.ca/english/care/report/1.html> Canadian Institute for Health Information. 2004. Health Care in Canada 2004. Chapter 4, "To Err Is Human ... In Canada Too." Ottawa: Canadian Institute for Health Information (http://www.cihi.ca) Robbins, A.S., L.Z. Rubenstein, K. R. Josephson, B.L. Schulman, D. Osterweil and G. Fine. 1989. "Predictors of Falls among Elderly People. Results of Two Population-Based Studies." Archives of Internal Medicine 149(7): 1628-33.

Salgado, R.I., S. R. Lord, F. Ehrlich, N. Janji and A. Rahman. 2004. "Predictors of Falling in Elderly Hospital Patients." Archives of Gerontology and Geriatrics 38(3): 213-9.

Vassallo, M., J.C. Sharma and S.C. Allen. 2002. "Characteristics of Single Fallers and Recurrent Fallers Among Hospital In-patients." Gerontology 48(3): 147-50.

\section{Alliance Healthcare Group Inc. Apothe Cap̃}

A Aunctional, cost-efective, Hoscital Phamacy Management Systom.

Pobyn Pobinson, President Allance Hoalthcare Group inc. 793 Wellingten Street. London, ON NEA 3SS
Phone: $519.439-6947$ Toll Free: 1 -80b-673-6jos Fax: $519.660-8563$

Emaiti robymoahginenet

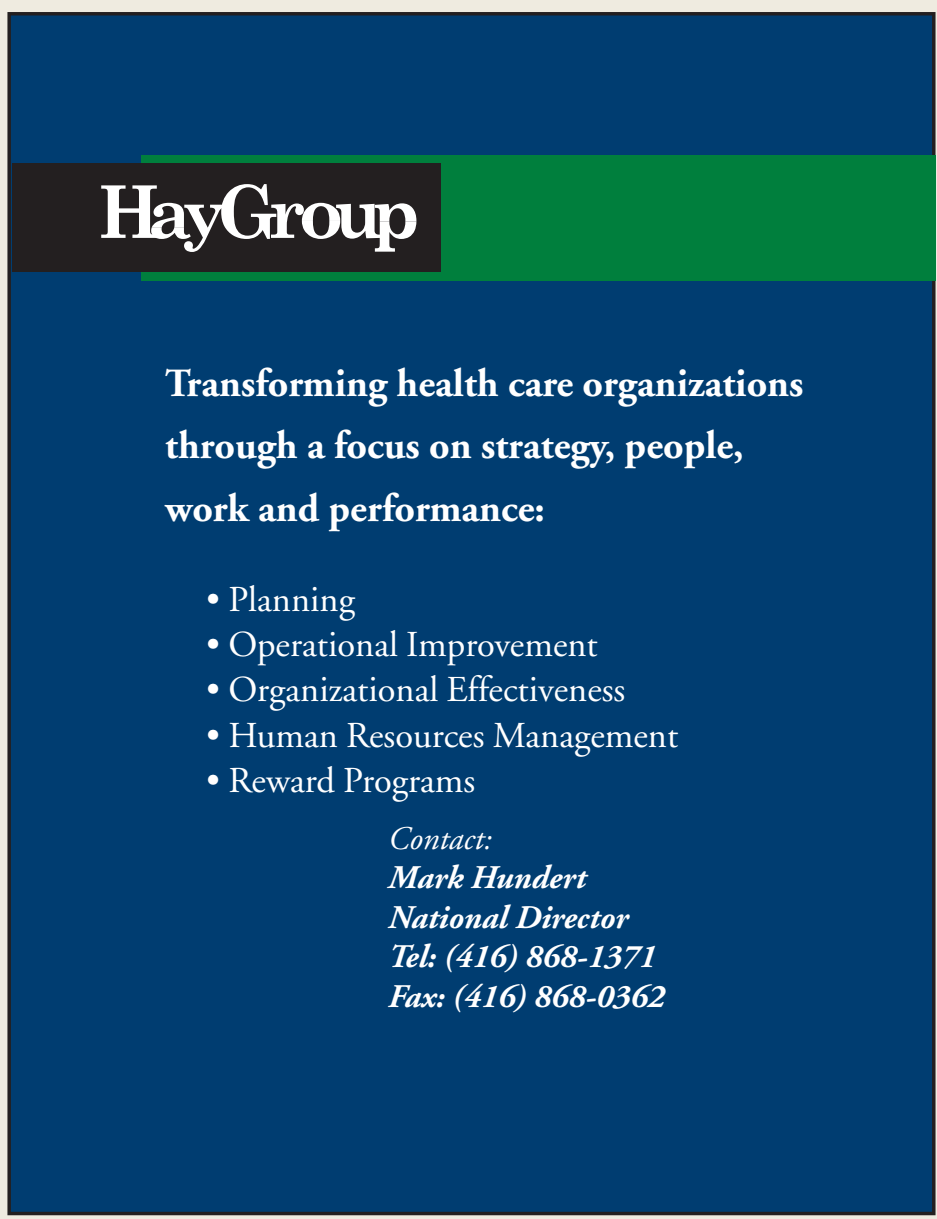

\section{Are you a physician leader?}

Increasingly physicians are seen as instrumental participants in the management of Canada's health care system. The Canadian Society of Physician Executives (CSPE) can offer physicians the opportunity to develop the necessary skills and gain knowledge to excel as leaders in these management positions.

Who should join

All physician managers, physician executives and any other physician interested in enhancing their effectiveness and involvement in system, institutional, organization or group management.

\section{Benefits of joining}

quarterly CSPE Newsletter - a highly valued information source for Canadian physician executives

- CSPE annual meeting - your opportunity to meet face-to-face with colleagues and learn from one another

physician management education - developed in collaboration with the Canadian Medical Association's Physician

Manager Institute (PMI) to provide you with the latest management skills and information

online Q\&A program - colleagues from around the country can provide answers to your most challenging management questions.

For more information contact

Canadian Society of Physician Executives, 1559 Alta Vista Drive, PO Box 59005, Ottawa ON K1G 5T7 613731-8610x2254・fax 613731-1779・carol.rochefort@cma.ca

\section{Visit our web site at www.cspexecs.com}

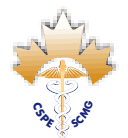

